\title{
Assurances du personnel attractives
}

\section{Afin que vous et vos collaborateurs payiez moins de primes}

Un rôle important des FMH Insurance Services est de négocier des conditions spéciales auprès des assurances pour le compte de l'association des médecins. Votre statut d'employeur vous oblige à assurer votre personnel. Ayant analysé un grand nombre d'offres, nous avons réussi à négocier un contrat-cadre attractif avec la Visana.

\section{Assurance-accidents obligatoire (LAA)}

Depuis bien deux ans déjà, les primes LAA ne se basent plus sur le tarif unique de l'Association Suisse d'Assurances mais sont fixées par les diverses sociétés elles-mêmes. Nombre d'assureurs n'ont à ce jour pas encore adapté leur taux de primes, ainsi une comparaison avec notre offre s'impose:

\begin{tabular}{|l|l|l|}
\hline & Notre prime en $\%$ du salaire & Répartition \\
\hline Accident prof. & $0,084 \%$ & $100 \%$ employeur \\
\hline Accident non-prof. & $1,077 \%$ & $100 \%$ employé (en règle générale) \\
\hline
\end{tabular}

\section{IJM - Assurance collective d'indemnités journalières en cas de maladie}

Selon le code des obligations, vous êtes dans l'obligation de continuer à verser le salaire à vos employés en cas d'incapacité de gain durant une période déterminée (selon la durée du contrat de travail). L'assurance d'indemnités journalières en cas de maladie vous permettrait de transférer ce risque sur un assureur. De plus, vos employés profiteraient ainsi d'une meilleure solution de prévoyance que celle fournie par les prestations légales minimales. Ce cas de figure peut parfois également présenter de grandes variations dans les taux de primes des différentes sociétés d'assurance:

\begin{tabular}{|l|l|l|}
\hline Délai d'attente & Notre prime en $\%$ du salaire & Répartition \\
\hline 14 jours & $1,21 \%$ & $\begin{array}{l}\text { en règle générale } 50 \% \text { employeur } \\
\text { et } 50 \% \text { employé }\end{array}$ \\
\hline 30 jours & $0,74 \%$ & \\
\hline 60 jours & $0,43 \%$ &
\end{tabular}

\section{Talon réponse}

Prénom / Nom

Adresse

NPA / Lieu

Date de naissance

Téléphone privé / cabinet

Atteignable le plus facilement (heure)

Adresse e-mail

Veuillez vérifier mes assurances et me faire parvenir une offre comparative. (Merci de nous annexer une copie de vos polices d'assurance actuelles.)

Je désire un conseil personnalisé.

Prière de $m^{\prime}$ appeler.

○ Je m'intéresse à:

\footnotetext{
$3^{e}$ pilier lié a

Planification financière

P Planification de la retraite

O

Caisse de pension LPP

O Responsabilité civile prof.

Assurance protection juridique
}

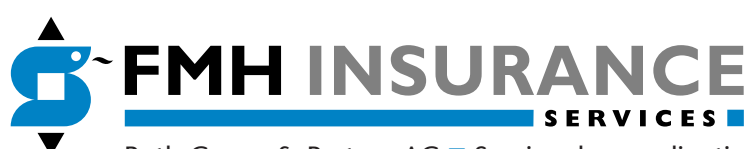

Roth Gygax \& Partner AG $\mathbf{r}$ Service de coordination Moosstrasse 2 a 3073 Gümligen

Téléphone 0319595000 — Fax 0319595010 mail@fmhinsurance.ch n www.fmhinsurance.ch 